AAS $98-145$

\title{
NAVIGATION FLIGHT OPERATIONS FOR MARS PATHFINDER
}

\author{
Robin M. Vaughan ${ }^{\dagger}$, Pieter H. Kallemeyn, Jr. ${ }^{\dagger}$, David A. Spencer ${ }^{*}$, \\ and Robert D. Braun
}

On July 4, 1997, Mars Pathfinder became the first spacecraft to land on the surface of Mars in 21 years. Pathfinder was launched on December 4, 1996 and spent seven months en route to the red planet. This report discusses the navigation flight experience for the Mars Pathfinder interplanetary cruise. In particular, orbit determination and maneuver design and execution results are presented. Special emphasis is given to the navigation role in the days and hours leading up to and including the Entry, Descent, and Landing (EDL) phase.

\section{INTRODUCTION AND MISSION OVERVIEW}

Mars Pathfinder was one of the first two missions to be launched under NASA's new Discovery Program. The mission was designed to demonstrate a low-cost, reliable system for entering the Martian atmosphere and placing a lander safely on the surface of Mars. Pathfinder also carried a science payload that returned data on Mars' atmosphere, meteorology, geology and morphology, and the elemental composition of rocks and soil near the lander. A key element of this payload was the Sojourner microrover which was the first mobile vehicle ever operated on the surface of another planet.

The spacecraft traveled along the transfer trajectory from Earth to Mars shown in Figure 1. During the seven-month journey between planets, the lander and its science payload were enclosed in an atmospheric deceleration module (backshell and heat shield) that was attached to a cruise stage as shown in Figure 2. The cruise stage contained the propulsion unit, star and sun sensors, solar arrays, and other subsystems needed to travel from Earth to Mars. The atmospheric deceleration module consisted of the backshell, heat shield, braking rockets, and parachute. The lander contained the flight computer, X-band radio system, and all engineering subsystems which were used during

\footnotetext{
† Senior Member of Engineering Staff, Navigation and Flight Mechanics Section, Jet Propulsion Laboratory, California Institute of Technology, Pasadena, California.

* Mars '01 Mission Manager, Jet Propulsion Laboratory, California Institute of Technology, Pasadena, California.

‡ Aerospace Engineer, Space Systems and Concepts Division, NASA Langley Research Center, Hampton, Virginia.
} 
surface operations. Telecommunications and navigation tracking during cruise were performed using an X-band radio system and medium gain antenna on the cruise stage. Navigation tracking data was limited to coherent, 2-way (X-band) Doppler and ranging.

The Pathfinder spacecraft entered the Martian atmosphere directly from its interplanetary trajectory. Initial deceleration in the atmosphere was accomplished by aerodynamic braking using the heatshield, followed by deployment of the parachute. Small braking rockets were fired at a specified altitude to null the remaining vertical velocity. Airbags were inflated surrounding the lander to cushion the surface impact, the lander was separated from the backshell and parachute, and allowed to free fall the rest of the way to the surface. The lander bounced at least 15 times before coming to rest on the surface. The airbags were then deflated and retracted, and the lander was configured to expose the payload and rover for surface operations.

There were 3 requirements on the navigation system for the Pathfinder mission. Two of these involved targeting the spacecraft for safe atmospheric entry from the interplanetary trajectory and landing at the desired location on the surface. ${ }^{1,2}$ The third requirement was a limit on the total $\Delta \mathrm{V}$ that could be expended for trajectory correction maneuvers (TCMs) over the course of the mission. A previous paper ${ }^{2}$ described the navigation system designed to meet these requirements and presented pre-launch analyses of system performance. This paper documents actual navigation performance for the mission. The first section is devoted to spacecraft orbit determination (OD) topics including force modeling, tracking data quality, and filter configuration. $\infty$ solutions for the designs of the 4 cruise TCMs are also presented. This is followed by a discussion on maneuver design computations and maneuver implementation modes. Trajectory targets and the computed velocity change vectors are given for each TCM. The design values are compared to actual values from OD solutions reconstructing maneuver execution. The third section discusses navigation activities for EDL; results of the final OD solutions using tracking data received up to the last minutes before atmospheric entry are presented. The final section gives conclusions on the overall Pathfinder navigation experience.

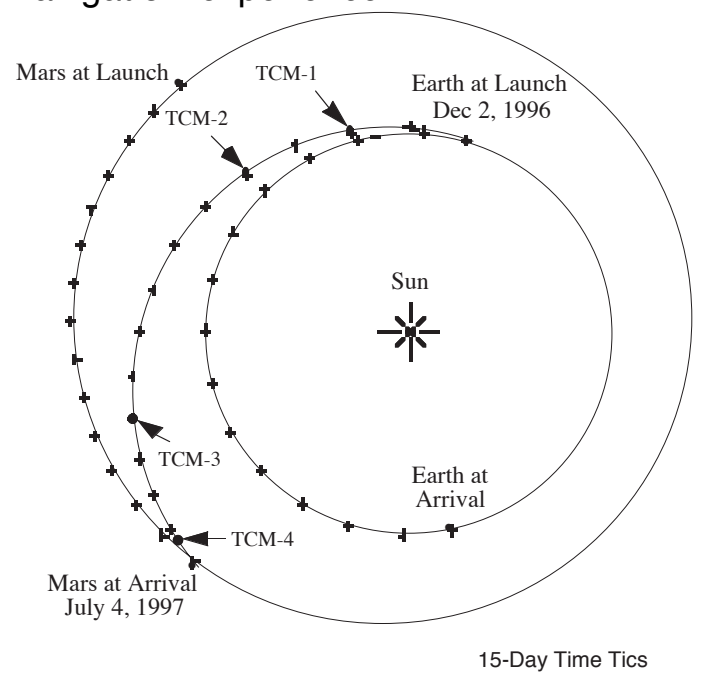

(Note: Actual launch date was December 4, 1996.)

Figure 1 Mars Pathfinder Interplanetary Trajectory

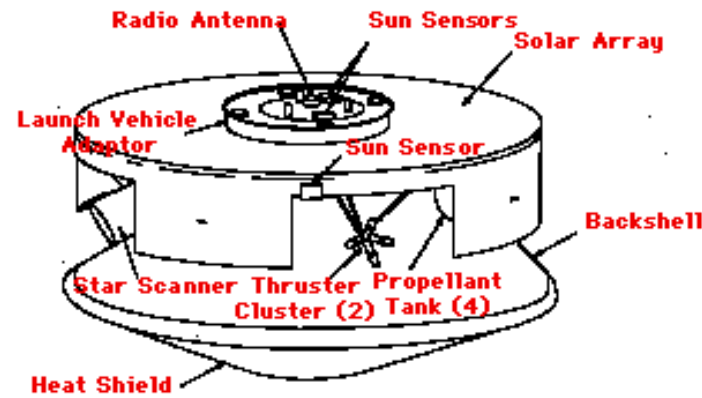

Figure 2 Mars Pathfinder Flight System 


\section{ORBIT DETERMINATION}

Two important aspects of the orbit determination (OD) task were spacecraft nongravitational force modeling and the quality of the radiometric tracking data. Overall force modeling is summarized and details are given on the evolution of the spacecraft component model for solar radiation pressure. Variations in Doppler and ranging data quality throughout the mission are shown and their impact on the orbit determination process is discussed. Modeling of error sources for the Doppler and ranging tracking data is described. The filter configuration for in-flight trajectory estimation is compared to the pre-launch plans. ${ }^{1,2}$ The results of orbit determination solutions for the designs of TCMs 1-4 are presented. (OD results from the last 48 hours before entry are covered in the section on navigation for EDL.)

\section{Non-Gravitational Force Models}

Other than the gravitational attraction of the Sun and planets, the only known forces acting on the Pathfinder spacecraft during cruise were thrusting events and solar radiation pressure. All attitude control turns and spin rate changes were modeled as "small forces" - instantaneous velocity changes with magnitudes ranging from 0.5 to 7 $\mathrm{mm} / \mathrm{sec}$. A total of 24 such events were eventually included in the filter runs, covering initial turns to reduce the spin rate from 12 to $2 \mathrm{rpm}$ after launch, 17 turns for pointing control during cruise, and cruise stage separation just prior to atmospheric entry. The four TCMs were modeled as a set of either finite or instantaneous burns, depending on their magnitude and execution mode. TCM 1 was modeled as one continuous finite burn since it was executed in one segment lasting about 90 minutes. The remaining 3 TCMs were each executed as multiple burn segments. TCM 2 was modeled as two finite burn segments, with the longest segment lasting approximately 5 minutes. TCMs 3 and 4 were modeled as 3 and 2 instantaneous burn segments, respectively; these were relatively small velocity changes with the segments completing in less than 30 seconds.

Solar radiation pressure contributed a small, but significant, continuous force on the spacecraft. Constructing the filter's solar pressure model proved more difficult than anticipated. The shape and reflectance properties of the spacecraft needed to be approximated in the orbit determination software using components of various standard types such as flat plates and cylinders. A key issue was the modeling for the backshell which has a non-standard shape and which was shaded by the cruise stage to a varying extent during most of the flight. The challenge was to choose a component type and size that captured the contribution of the solar pressure from the illuminated portion of the backshell. An additional complication was the inability of the software to model the effects of shading due to changing attitude and component configuration.

Ultimately, a total of four solar pressure component models were used during flight. ${ }^{3}$ All of the models used a flat plate to represent the solar array disk of the cruise stage. The launch vehicle adapter and the heat rejection system (HRS) panels, also on the cruise stage, were represented by another flat plate and a cylinder in the later models. The primary difference in the models was the treatment of the backshell. The first and fourth models used a flat plate active for the entire cruise. In contrast, the intermediate models invoked the navigation software's ability to limit the time span over which a given component contributes to the solar pressure force. The second model represented the backshell as a flat plate active only after March 1997. The third model used two separate components for the backshell: a cylinder active before April 1997 and a flat 
plate active thereafter. These were attempts to account for the changing solar illumination on the backshell; the orientation of each component relative to the cruise stage components as well as the time of activating components was based on the history of the solar aspect angle over the mission.

Various problems with the filter solutions were encountered when using each of these models. Solutions using the early models and estimating reflectance coefficients and area scale factors for each component failed to produce a predicted future trajectory consistent with the actual tracking data received after the cutoff for those solutions. Also, solutions would often produce corrections for the reflectance coefficients that would make the new values physically impossible. Experimentation with the filter eventually yielded reasonable results with good fits through new data when only the area scale factors for each component were estimated. These were the only solar pressure parameters included in the OD solutions supporting TCM 4 design and EDL. A more serious problem involving switching component types for the backshell was uncovered during the last week before entry. Deleting a single pass of Doppler data occurring near the April 16th transition date for the backshell component resulted in a significant shift in predicted Mars B-plane state. The elimination of these few dozen points over the data arc running from February to June should not have made such a large change in the solutions. Experiments showed that identical results were obtained if only a single set of components were active for the entire data arc, regardless of whether or not that Doppler pass was included. Based on this observation, the navigation team opted to model the backshell as a flat plate over the entire data arc for all OD solutions following TCM 4 execution and leading up to EDL.

Small modeling errors and potential unknown forces (such as outgassing) were accommodated in the filter by including a set of stochastic non-gravitational accelerations. These parameters were tightly constrained by the choice of a priori sigmas so that they were not confused with known forces already in the filter model.

\section{Radiometric Data Quality}

The quality of the radiometric tracking data was crucial to obtaining the required navigation accuracy for Mars Pathfinder. The enhanced filter configuration depended on low-noise, high-precision ranging measurements to safely meet the atmospheric entry trajectory requirements. Unfortunately, ranging performance was beset with a series of problems during the first 6 months of cruise, including unexpected biases and high noise levels. In contrast, the Doppler system performed well throughout the flight. The only significant influence on Doppler data quality was the signature imposed by spinning the spacecraft.

The Mars Pathfinder spacecraft was spin-stabilized, constantly rotating about an axis pointing upward through the center of the aeroshell, roughly normal to the circular solar array panel. The polarization of the radio signals and a slight offset of the antenna boresight from the spin axis resulted in both a fixed bias and an amplitude modulation appearing in the 2-way Doppler data. ${ }^{4}$ The Delta launch vehicle released the spacecraft with the spin axis pointed towards the sun. The original plan was to orient the spacecraft such that the spin axis was very nearly Earth-pointed during the first week after launch and to maintain that attitude throughout cruise. The Doppler amplitude modulation is negligible for small off-Earth angles and the navigation team intended to ignore it when processing the data. However, problems with the sun sensors resulted in the spacecraft 
being kept in its Sun-pointed attitude until just after the execution of TCM 1 on January 10, 1997. Thus, for the first 30 days after launch, Doppler amplitude modulation due to changing Earth aspect angle was clearly visible in the Doppler data and was used to verify the post-launch spin rates and spacecraft attitudes.

Figure 3 shows the post-fit Doppler residuals over the entire cruise period from launch to entry (December 1996 - July 1997). The spin signature due to off-Earth pointing is clearly seen in the passes before TCM 1 which have larger scatter, ranging from 0.01 to $0.03 \mathrm{~Hz}(0.18$ to $0.53 \mathrm{~mm} / \mathrm{s})$. Early OD solutions treated this signature as simply an increase in data noise and the data were consequently deweighted. Typical Doppler weights for the period before TCM 1 were between 0.10 and $0.025 \mathrm{~Hz}(1.8$ and $0.44 \mathrm{~mm} / \mathrm{s}$ ), assuming a $60-\mathrm{sec}$ count time. The Doppler passes in Figure 2.2 after TCM 1 appear much more compact, signaling the return to an Earth-pointed attitude. The scatter of points within each pass decreased to $0.00173 \mathrm{~Hz}(0.031 \mathrm{~mm} / \mathrm{s})$ between TCMs 1 and 2. The Doppler noise level continued to decrease, averaging $0.0010 \mathrm{~Hz}$ ( $0.018 \mathrm{~mm} / \mathrm{s})$ per pass between TCMs 2 and 3 and $0.0014 \mathrm{~Hz}(0.025 \mathrm{~mm} / \mathrm{s})$ per pass after TCM 3. These later Doppler data were ultimately weighted at $0.006 \mathrm{~Hz}(0.11$ $\mathrm{mm} / \mathrm{s}$ ), again assuming a $60-\mathrm{sec}$ count time.

The constant bias imparted by the spinning spacecraft has been removed from the data before filtering so that it does not appear in Figure 3. At the nominal spin rate of 2 $\mathrm{rpm}$, the expected value of the bias is $0.0725 \mathrm{~Hz}$. However, the spacecraft attitude control system did not maintain the spin rate exactly at this value. A stochastic Doppler bias parameter was routinely added to the $\mathrm{OD}$ solutions to account for slight differences between the actual spin rate and the value assumed for the pre-applied constant bias. The time history of this parameter in later OD solutions showed a consistently non-zero and predictable trend. This prompted an update to the pre-applied Doppler bias model based on the actual history of spin rate values from spacecraft telemetry. The final, critical OD solutions for EDL used a linearly varying bias between TCM 2 and 3 and a constant bias for a spin rate slightly below $2 \mathrm{rpm}$ thereafter. Constant biases were also applied for known spin rate values in the period before TCM 2 .
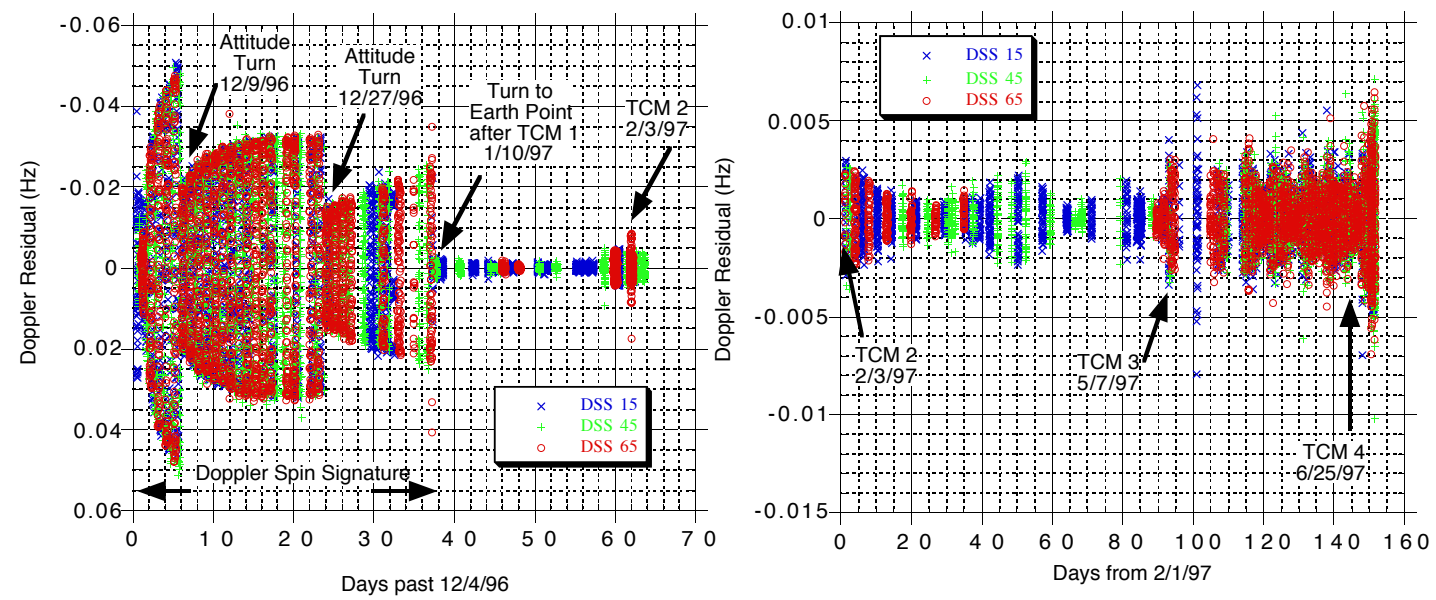

Figure 3 Post-fit Doppler residuals from launch to Mars arrival

Pre-launch requirements levied on the ranging system imposed a $1 \sigma$ noise (or jitter) level no greater than $1.0 \mathrm{~m}(\sim 7$ Range Units or $R U)$ within each pass. However, 
the range noise persisted at higher levels until late May as seen in Figure 4 which plots the the post-fit ranging residuals for the entire cruise." The first data returned after launch exhibited $1 \sigma$ noise between 13 and $27 \mathrm{RU}(1.86-3.8 \mathrm{~m})$. The noise decreased after TCM 1 when the spacecraft was oriented to an Earth-pointing attitude. The DSN ranging system uses the Doppler signal to assist in forming the ranging measurements and the spin signature imposed on the Doppler evidently degraded the early ranging measurements. Although the noise level had improved after TCM 1, it remained slightly above the desired value, varying between 7.4 and $11.7 \mathrm{RU}(1.06-1.67 \mathrm{~m})$, until March. Following nominal operational plans, the spacecraft's ranging system configuration was changed at this time, significantly lowering the $1 \sigma$ range noise level for passes from DSS 45 (Canberra, Australia) and DSS 65 (Madrid, Spain) to $2.23 \mathrm{RU}$ $(0.32 \mathrm{~m})$. But the passes from DSS 15 (Goldstone, CA) remained at a high noise level, eventually increasing to about $23.3 \mathrm{RU}(3.3 \mathrm{~m})$ by the end of May. A concentrated effort by DSN personnel eventually traced this problem to a faulty hardware component at DSS 15. This component was replaced by May 30 , and subsequent ranging passes from DSS 15 had noise levels comparable to the other two DSN sites. The last 35 days of ranging data before Mars arrival had an average $1 \sigma$ per-pass noise of $4.0 \mathrm{RU}(0.57 \mathrm{~m})$, well within the required level.

The range data weight in $\mathrm{OD}$ solutions was varied throughout the data arc to account for the changing noise level. Data before March 7 were typically weighed at $21 \mathrm{RU}$ ( 3 $\mathrm{m})$. DSS 15 range data continued to be weighed at this larger value up to May 30 , while DSS 45 and 65 data were weighed more tightly at just $4 \mathrm{RU}(0.57 \mathrm{~m})$. After May 30 , data from all sites was weighed at $4 \mathrm{RU}$.
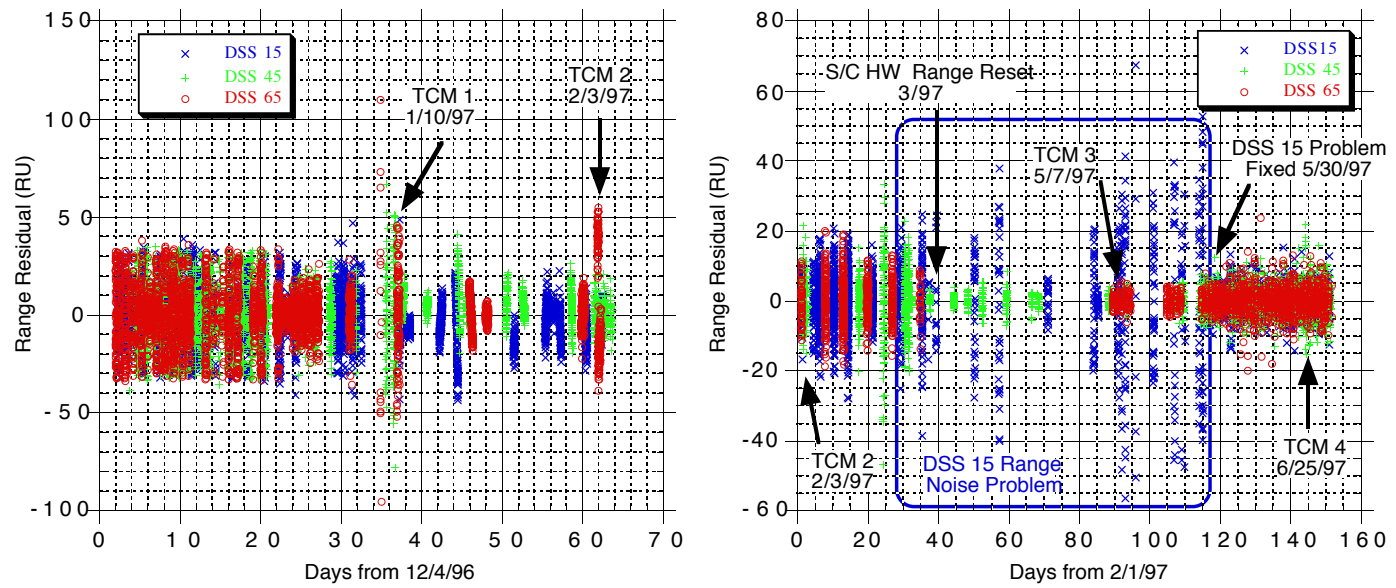

Figure 4 Post-fit range residuals from launch to Mars arrival

Ranging biases of various types were routinely employed as part of the OD filtering strategy. These included a bias of constant value for all ranging data and stochastic biases whose values varied for each pass. Pre-launch expected values for the pass-dependent

\footnotetext{
* The residuals in Figure 4 are zero-mean since biases for each pass were estimated in the filter solution. Plots of residuals without these biases are presented in Figure 5 as part of the discussion on ranging biases.
} 
biases were on the order of $10 \mathrm{RU}$. In-flight $\mathrm{OD}$ solutions consistently yielded values from 20-50 RU for these biases. The apriori sigma for these parameters in the $\mathrm{O}$ filter was increased to $40 \mathrm{RU}$ to reflect these larger values

Fixed biases for all passes from a specific DSS site were also available in the $\mathrm{C}$ software, but it was expected that these site-dependent biases would not be needed. However, in the weeks between TCM 1 and 2 it became apparent that the ranging data from DSS 15 was offset off from the DSS 45 and 65 data by a rather large amount. This is illustrated in Figure 5 which shows post-fit ranging residuals over the mission without any estimated biases. A similar situation occurred between TCM 2 and 3 where the DSS 45 data appeared biased from the DSS 15 and 65 data (not shown in Figure 5 ). The causes of these biases were identified and appropriate biase values were applied to the affected passes in subsequent OD solutions. A final site-dependent bias was observed in the last 35 days of tracking data between the DSS 65 ranging passes and the 15 and 45 passes. The cause of this last bias was unresolved before landing and a set of sitedependent range biases was added to the final OD solutions to account for it. The apriori sigma on the DSS 15 and 45 bias parameters was set at $7 \mathrm{RU}$; while the DSS 65 parameter's sigma was set at $30 \mathrm{RU}$. The estimated value of the DSS 65 bias in these runs ranged from -15 to $-20 \mathrm{RU}$ relative to the DSS 15 and 45 passes.
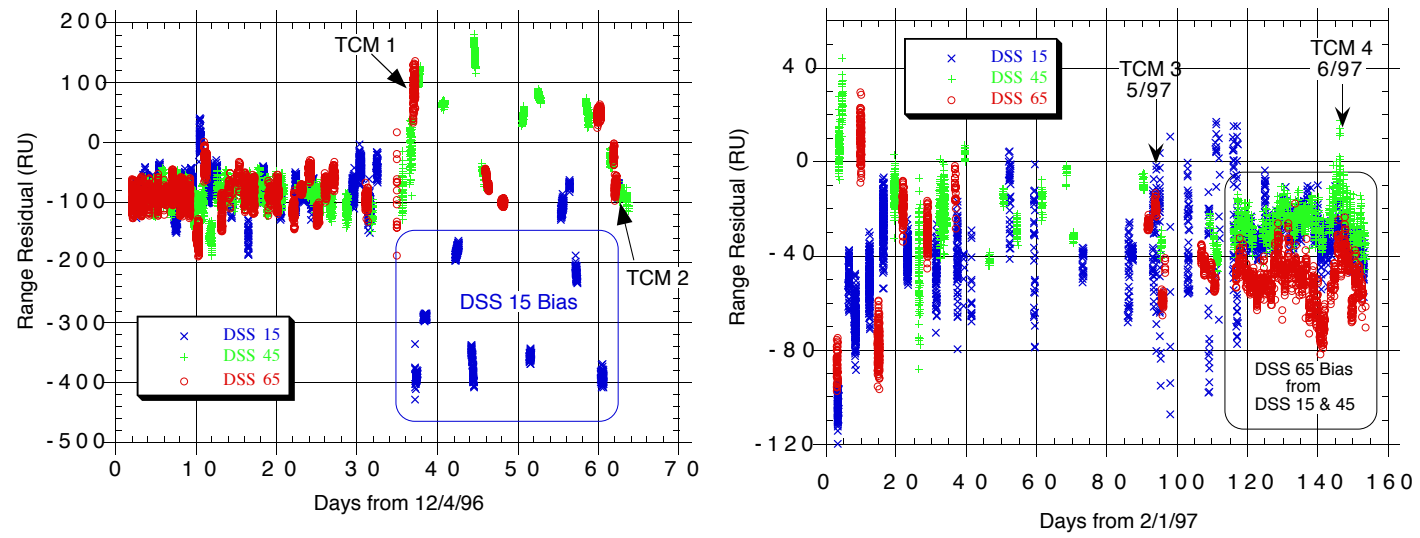

Figure 5 Range residuals from launch to Mars arrival without estimated range biases

\section{Orbit Determination Filter Configuration}

Traditional orbit determination filters have been configured with a mix of (constant) bias, stochastic and considered parameters. The set of bias parameters typically includes the known non-gravitational forces acting on the spacecraft. Pathfinder's OD runs followed this pattern, estimating solar pressure, velocity changes from TCMs and attitude control events, and the spacecraft epoch state as bias parameters. DSN station locations were also estimated as bias parameters as were Earth and Mars ephemeris parameters in runs performed within 10 days of arrival. The Pathfinder filter configuration differed from the traditional approach in that there were no consider parameters. Instead, new stochastic parameters were introduced to model data error sources that were formerly treated as consider parameters. An important group of these new stochastic parameters were the pass-dependent biases for the range and Doppler 
data. The introduction of these biases for the range data is called the precision range technique and allowed the data to be weighted at its inherent accuracy of a few meters. The pass-dependent Doppler biases were included to account for small deviations from the nominal spin rate. Constant biases were sometimes used in combination with these stochastic biases. A constant range bias for spacecraft hardware delays and constant biases for each of the DSN sites were used in some runs. Atmospheric media transmission effects on the radio signal and Earth timing and polar motion parameters were also treated as stochastic parameters. The remaining stochastic parameters were components of accelerations acting in the radial and transverse directions. One or all of these components were included to account for small, unknown errors in the force model. The success of Pathfinder navigation has provided valuable in-flight validation of this enhanced filter configuration, with its associated precision ranging technique. ${ }^{1,2,5,6}$

The filter configuration for the OD solutions selected for the final design each of the 4 TCMs is summarized in Table 1. In general, this proved remarkably similar to the pre launch planned configuration. ${ }^{2}$ The two major changes over the course of the mission were the set of solar pressure parameters and data biases. OD runs for TCMs 1 and 2 used earlier solar pressure models having fewer components; area scale factors and reflectance coefficients for each component were estimated. Runs for TCMs 3 and 4 used later models and estimated only the area scale factors for their components. Passdependent Doppler biases were used up to the run for TCM 4 design. The new Doppler spin signature model was introduced at this time, replacing these stochastic parameters with more accurate pre-applied adjustments and a single stochastic Doppler bias parameter. The pass-dependent range biases were augmented with site-dependent biases to accommodate the observed range data behavior. A similar configuration was adopted for subsequent OD runs supporting critical EDL operations; this configuration is highlighted by the shaded lines in Table 1. (Representative data weights were presented in the preceding sections).

\section{Orbit Determination Results for TCM Designs}

The results of the OD solutions for design of TCMs 1-4 are summarized in Table 2. Predicted spacecraft state at Mars arrival is given as coordinates in a Mars-centered B plane coordinate system. The B-plane is perpendicular to the incoming asymptote of the spacecraft's trajectory (called the $S$ direction) and contains the two axes $R$ and $T$. $T$ is defined as the intersection of the B-plane with the Mars mean equator of date. Predicted position in the B-plane is given in Table 2 as a pair of $R$ and $T$ coordinates for the location where the asymptote intersects the B-plane. The vector pointing from the origin of the $R$ and $T$ axes (Mars center) to the predicted B-plane position is call the miss vector or B-vector. Uncertainty in B-plane position is represented by the size and orientation of a $1 \sigma$ error ellipse around the predicted position. The size of these ellipses are given as semi-major and semi-minor axis lengths (SMAA \& SMIA), while the ellipse orientation is given by the angle to the semi-major axis direction measured clockwise from the $\mathrm{T}$ axis $(\theta)$. Predicted position in the $\mathrm{S}$ direction is given in Table 2 by the time of closest approach (TCA) and its associated $1 \sigma$ uncertainty. 
Table 1 OD FILTER CONFIGURATION FOR TCM DESIGN AND EDL RUNS

\begin{tabular}{|c|c|c|c|c|}
\hline Filter Parameter & $\begin{array}{c}\text { a priori } \\
\text { uncertainty } \\
(1 \sigma)\end{array}$ & $\begin{array}{l}\text { Process Noise } \\
\text { (N/A for bias } \\
\text { parameters) }\end{array}$ & $\begin{array}{l}\text { Correlation time } \\
\text { (N/A for bias } \\
\text { parameters) }\end{array}$ & Comments \\
\hline \multicolumn{5}{|l|}{ Bias (Constant) } \\
\hline S/C Epoch State & $\begin{array}{l}\text { position - } 1000 \mathrm{~km} \\
\text { velocity - } 1.0 \mathrm{~km} / \mathrm{sec}\end{array}$ & $\mathrm{N} / \mathrm{A}$ & $\mathrm{N} / \mathrm{A}$ & All runs \\
\hline $\begin{array}{l}\text { Solar Pressure } \\
\text { Area Scale Factors }\end{array}$ & $\begin{array}{l}1.5-50 \% \text { of nominal } \\
(0.015,0.05,0.50)\end{array}$ & $\mathrm{N} / \mathrm{A}$ & $\mathrm{N} / \mathrm{A}$ & All runs \\
\hline Specular Reflectivity & $0.0116-0.0165$ & $\mathrm{~N} / \mathrm{A}$ & $\mathrm{N} / \mathrm{A}$ & $\begin{array}{l}\text { TCM } 1 \& 2 \\
\text { runs }\end{array}$ \\
\hline Diffuse Reflectivity & $\begin{array}{l}0.02-0.10 \\
(0.0697, \quad 0.0999 \\
0.02, \quad 0.1)\end{array}$ & $\mathrm{N} / \mathrm{A}$ & $\mathrm{N} / \mathrm{A}$ & $\begin{array}{l}\mathrm{TCM} 1,2, \& \\
3 \text { runs }\end{array}$ \\
\hline Earth/Mars ephemeris & $\begin{array}{c}\text { Mars: } 1.0 \text { (radial) } \\
7.0 \text { (transverse) } \\
7.0 \text { (normal) } \\
\end{array}$ & $\mathrm{N} / \mathrm{A}$ & $\mathrm{N} / \mathrm{A}$ & $\begin{array}{l}\text { TCM 4, } \\
\text { EDL runs }\end{array}$ \\
\hline $\begin{array}{l}\text { TCMs } \\
\text { TCM } 1 \text { - } 1 \text { finite burn }\end{array}$ & $\begin{array}{l}\text { pointing }-0.5 \mathrm{deg} \\
\text { magnitude }-5 \%\end{array}$ & $\mathrm{~N} / \mathrm{A}$ & $\mathrm{N} / \mathrm{A}$ & TCM 2 runs \\
\hline TCM 2 - 2 finite burns & & $\mathrm{N} / \mathrm{A}$ & $\mathrm{N} / \mathrm{A}$ & \\
\hline TCM 3 - 3 inst burns & $2 \%$ in $\Delta \mathrm{V}$ components & $\mathrm{N} / \mathrm{A}$ & $\mathrm{N} / \mathrm{A}$ & $\begin{array}{l}\text { TCM } 4 \text { \& EDL } \\
\text { runs }\end{array}$ \\
\hline TCM $4-2$ inst burns & $\begin{array}{l}3.33 \% \text { in } \Delta \mathrm{V} \\
\text { components }\end{array}$ & $\mathrm{N} / \mathrm{A}$ & $\mathrm{N} / \mathrm{A}$ & EDL runs \\
\hline Attitude Control $\Delta \mathrm{Vs}$ & $2.0 \mathrm{E}-6 \mathrm{~km} / \mathrm{sec}$ & $\mathrm{N} / \mathrm{A}$ & $\mathrm{N} / \mathrm{A}$ & All runs \\
\hline S/C Range Bias & $\begin{array}{l}400-1000 \mathrm{RU} \\
(57-143 \mathrm{~m})\end{array}$ & $\mathrm{N} / \mathrm{A}$ & $\mathrm{N} / \mathrm{A}$ & $\begin{array}{l}\text { TCMs } 1,2, \\
\& 4 \text { and EDL } \\
\text { runs }\end{array}$ \\
\hline Site Range Biases & $\begin{array}{l}7 \mathrm{RU}(1 \mathrm{~m}) \mathrm{DSS} 15,45 \\
30 \mathrm{RU}(4.3 \mathrm{~m}) \mathrm{DSS} 65 \\
\end{array}$ & $\mathrm{~N} / \mathrm{A}$ & $\mathrm{N} / \mathrm{A}$ & $\begin{array}{l}\text { TCM } 4 \& \mathrm{EDL} \\
\text { runs }\end{array}$ \\
\hline Station locations & $10 \mathrm{~cm}$ & $\mathrm{~N} / \mathrm{A}$ & $\mathrm{N} / \mathrm{A}$ & All runs \\
\hline \multicolumn{5}{|l|}{ Stochastic } \\
\hline Radial Accels & $1-5 \mathrm{E}-6 \mathrm{~mm} / \mathrm{sec}^{2}$ & $\begin{array}{l}1-5 \mathrm{E}-12 \\
\mathrm{~km} / \mathrm{sec}^{2} \\
\end{array}$ & 0 (white noise) & All Runs \\
\hline Transverse Accels & $1-5 \mathrm{E}-6 \mathrm{~mm} / \mathrm{sec}^{2}$ & $\begin{array}{l}1-5 \mathrm{E}-12 \\
\mathrm{~km} / \mathrm{sec}^{2}\end{array}$ & 0 (white noise) & $\begin{array}{l}\text { TCM } 2 \& 3 \\
\text { runs }\end{array}$ \\
\hline Pass Range Biases & $40 \mathrm{RU}(5.7 \mathrm{~m})$ & $40 \mathrm{RU}(5.7 \mathrm{~m})$ & Variable & All runs \\
\hline Pass Doppler Biases & $\begin{array}{l}0.05 \mathrm{~Hz} \\
(0.89 \mathrm{~mm} / \mathrm{sec})\end{array}$ & $\begin{array}{l}0.05 \mathrm{~Hz} \\
(0.89 \mathrm{~mm} / \mathrm{sec})\end{array}$ & Variable & $\begin{array}{l}\text { TCMs } 1,2,3 \\
\text { runs }\end{array}$ \\
\hline $\begin{array}{l}\text { Doppler Bias } \\
\text { (spin signature) }\end{array}$ & $\begin{array}{l}0.0007 \mathrm{~Hz} \\
(0.01246 \mathrm{~mm} / \mathrm{sec})\end{array}$ & $0.0007 \mathrm{~Hz}$ & 15 days & $\begin{array}{l}\text { TCM } 4 \text { \& EDL } \\
\text { runs }\end{array}$ \\
\hline Troposphere & $5 \mathrm{~cm}$ & $5 \mathrm{~cm}$ & 3 hours & All runs \\
\hline lonosphere & $\begin{array}{l}4 \mathrm{~cm} \text { (day) } \\
1 \mathrm{~cm} \text { (night) }\end{array}$ & $\begin{array}{l}4 \mathrm{~cm} \text { (day) } \\
1 \mathrm{~cm} \text { (night) }\end{array}$ & $\begin{array}{l}5 \text { hours (day) } \\
24 \text { hours (night) }\end{array}$ & All runs \\
\hline Polar motion & $10 \mathrm{~cm}$ & $10 \mathrm{~cm}$ & 48 hours & All runs \\
\hline Earth rotation & $0.001 \mathrm{sec}$ & $0.001 \mathrm{sec}$ & 24 hours & All runs \\
\hline
\end{tabular}


Table 2 B-PLANE STATE, TIME OF CLOSEST APPROACH, AND THEIR $1 \sigma$ UNCERTAINTIES FOR CRUISE OD SOLUTIONS

\begin{tabular}{|c|c|c|c|c|}
\hline $\begin{array}{c}\mathrm{OD} \\
\text { Solution }\end{array}$ & Data Arc & $\begin{array}{l}\mathrm{B} \cdot \mathrm{R} \\
(\mathrm{km})\end{array}$ & $\begin{array}{l}\mathrm{B} \cdot \mathrm{T} \\
(\mathrm{km})\end{array}$ & $\begin{array}{c}\text { TCA } \\
\text { (UTC) } \\
\end{array}$ \\
\hline TCM 1 & $\begin{array}{l}12 / 9 / 96-1 / 2 / 97 \\
\text { (24 days) }\end{array}$ & 279321.23 & 386696.07 & $7 / 3 / 97 \quad 09: 14: 57$ \\
\hline TCM 2 & $\begin{array}{l}12 / 4 / 96-1 / 26 / 97 \\
\text { (53 days) }\end{array}$ & 8491.72 & 9767.62 & $7 / 4 / 97 \quad 15: 45: 26$ \\
\hline TCM 3 & $\begin{array}{l}2 / 4 / 97-4 / 29 / 97 \\
\text { (84 days) }\end{array}$ & -1790.15 & -4494.02 & $7 / 4 / 97 \quad 16: 52: 52$ \\
\hline TCM 4 & $\begin{array}{l}2 / 4 / 97-6 / 23 / 97 \\
\text { (139 days) }\end{array}$ & -1852.63 & -4250.28 & $7 / 4 / 97 \quad 16: 54: 21$ \\
\hline $\begin{array}{c}\mathrm{OD} \\
\text { Solution }\end{array}$ & $\begin{array}{c}1 \sigma \text { SMAA } \\
(\mathrm{km})\end{array}$ & $\begin{array}{c}1 \sigma \text { SMIA } \\
(\mathrm{km})\end{array}$ & $\begin{array}{c}\theta \\
(\mathrm{deg})\end{array}$ & $\begin{array}{c}1 \sigma \mathrm{TCA} \\
(\mathrm{sec})\end{array}$ \\
\hline TCM 1 & 100.64 & 11.066 & 24.44 & 25.93 \\
\hline TCM 2 & 249.03 & 234.915 & 31.54 & 80.02 \\
\hline TCM 3 & 34.49 & 30.717 & 106.99 & 6.21 \\
\hline TCM 4 & 17.44 & 4.192 & 109.59 & 0.38 \\
\hline
\end{tabular}

\section{MANEUVER DESIGN AND EXECUTION}

Four trajectory correction maneuvers (TCMs) were planned and executed during cruise, the first two within 60 days of launch and the last two within 60 days of Mars arrival. This section discusses the choice of target aimpoints, the computation of required velocity changes, and implementation modes for each of these maneuvers. Maneuver performance is summarized by comparing design velocity changes with $\mathrm{O}$ estimates of the actual changes based on tracking data taken during and after the maneuvers. The actual total velocity change implemented for the mission is compared to the pre-launch budget statistics. ${ }^{2,7}$

\section{Target Aimpoints and Designed Velocity Changes}

The target trajectory conditions for TCMs 1-4 are presented in Table 3 as $B \cdot R$ and $B \cdot T$ coordinates in the Mars-centered B-plane coordinate system and an associated time of closest approach to Mars. These quantities are chosen for ease of comparison with the OD solution results given in Table 2. The launch injection target was biased away from the required atmospheric entry aimpoint to minimize the probability of the launch vehicle upper stage impacting Mars. The targets for TCMs 1 and 2 were to remove this bias, but could themselves be biased from the final aimpoint in order to minimize the probability of the spacecraft impacting the Martian surface at a speed greater than 1000 $\mathrm{ft} / \mathrm{sec}$. Analysis of the actual injection accuracy and OD knowledge at the time of TCM 1 design showed that the impact speed constraint would be satisfied without adding any bias to the direct entry target point. This is the reason that the target aimpoint for TCM 1 listed in Table 3.2 is very close to that of TCMs 3 and 4 . Subsequent OD solutions reflecting TCM 1 execution showed that this second bias would have to be put back in to satisfy the surface impact speed constraint at the time of TCM 2 design, so its target parameters differ significantly from those of the other 3 maneuvers. 
Targeting for TCMs 1, 3 and 4 was based on desired flight-path angle at a specified altitude above Mars and landing site latitude and longitude. OD solutions provided the estimated arrival geometry and time at the selected Mars atmospheric interface altitude. The descent trajectory through the atmosphere then determined the landing site associated with this arrival point. A special program - the Atmospheric Entry Program or (AEP) - was used to model the trajectory dynamics during descent and to target to the desired landing site. ${ }^{8}$ The program SEPV of the DPTRAJ software set was used to target the interplanetary trajectory to the required atmospheric interface geometry. ${ }^{9}$ The B plane coordinates and arrival time associated with the desired descent and landing conditions were obtained through iterative application of these two programs. ${ }^{10}$ SEPV was also used to calculate the required velocity change $(\Delta \mathrm{V})$ vector for each maneuver. The current best estimate of the orbit, the nominal time of the TCM and the desired TCM target were used together to calculate the required instantaneous $\Delta \mathrm{V}$. The times and overall design $\Delta \mathrm{V}$ vectors for each TCM are listed in Table 4.*

Table 3 B-PLANE AND TIME OF CLOSEST APPROACH TARGETS AND SHIFTS FOR TCMS 1-4

\begin{tabular}{|c|l|c|c|c|}
\hline Maneuver & \multicolumn{1}{|c|}{ Date } & $\begin{array}{c}\text { Target B } \cdot \mathrm{R} \\
(\mathrm{km})\end{array}$ & $\begin{array}{c}\text { Target B・T } \\
(\mathrm{km})\end{array}$ & $\begin{array}{c}\text { Target TCA } \\
(\text { UTC on } 7 / 4 / 97)\end{array}$ \\
\hline \hline TCM 1 & $\begin{array}{l}\text { Launch }+37 \text { days } \\
1 / 10 / 97\end{array}$ & -1856.93 & -4263.91 & $16: 53: 43.20$ \\
\hline TCM 2 & $\begin{array}{l}\text { Launch }+61 \text { days } \\
2 / 3 / 97\end{array}$ & -2004.00 & -4554.00 & $16: 53: 43.26$ \\
\hline TCM 3 & $\begin{array}{l}\text { Mars }-58 \text { days } \\
5 / 7 / 97\end{array}$ & -1855.60 & -4264.16 & $16: 54: 22.128$ \\
\hline TCM 4 & $\begin{array}{l}\text { Mars }-9 \text { days } \\
6 / 25 / 97\end{array}$ & -1855.60 & -4264.16 & $16: 54: 22.128$ \\
\hline
\end{tabular}

\section{Maneuver Execution Modes}

The Pathfinder propulsion system had two sets of thrusters: the axial set producing thrusts aligned with the spin axis of the spacecraft and the lateral set producing thrusts roughly perpendicular to the spin axis. Depending on the spacecraft's attitude relative to the direction of the desired $\Delta \mathrm{V}$ vector, one or both of these sets could be fired to add vectorially to the total $\Delta \mathrm{V} .^{2,7} \mathrm{TCM} 1$ was implemented using only a single session of axial thruster firing. This could also have been done for TCM 2, but both lateral and axial thrusting would be necessary for TCMs 3 and 4 given the preferred spacecraft attitude for late cruise. Since these TCMs were critical for Mars atmospheric entry targeting, it was decided to test lateral thrusting at TCM 2. The spacecraft orientation for TCM 2 was chosen such that the lateral segment would match the expected magnitude of TCM 3 . The axial segment was performed first followed by the lateral pulsing segment. The lateral portion of TCM 2 executed as desired, validating its use in combination with axial thrusting for TCMs 3 and 4.

\footnotetext{
* The maneuver design calculations assumed instantaneous application of the total $\Delta \mathrm{V}$, but the spacecraft's propulsion system actually took a finite amount of time to implement these burns. For this reason, some of the larger maneuvers were modeled as burns of finite, non-zero duration in the OD filter, as previously described.
} 
Table 4 Design \& Estimated Values of Overall Velocity Change $(\Delta \mathrm{V})$ Vectors for TCMs 1-4

\begin{tabular}{|c|c|c|c|c|c|}
\hline \multirow[t]{2}{*}{ Maneuver } & \multirow{2}{*}{$\begin{array}{c}\text { Design } \\
\text { Execution Time } \\
\text { (UTC) } \\
\end{array}$} & \multicolumn{4}{|c|}{ Design $\Delta \mathrm{V}$ Vector in EME2000 (Inertial) Coordinates } \\
\hline & & $\begin{array}{c}\mathrm{X} \\
(\mathrm{m} / \mathrm{sec}) \\
\end{array}$ & $\begin{array}{c}\mathrm{Y} \\
(\mathrm{m} / \mathrm{sec}) \\
\end{array}$ & $\begin{array}{c}\mathrm{Z} \\
(\mathrm{m} / \mathrm{sec}) \\
\end{array}$ & $\begin{array}{c}\begin{array}{c}\text { Magnitude } \\
(\mathrm{m} / \mathrm{sec})\end{array} \\
\end{array}$ \\
\hline TCM 1 & $1 / 10 / 97 \quad 02: 00$ & 17.301 & -25.321 & 5.899 & 31.229 \\
\hline TCM 2 & $2 / 3 / 97 \quad 23: 00$ & 1.1193 & -1.1231 & 0.0352 & 1.5860 \\
\hline TCM 3 & $5 / 7 / 97$ & 0.0762 & 0.0630 & 0.0362 & 0.1053 \\
\hline TCM 4 & $6 / 25 / 97 \quad 17: 00$ & 0.0105 & -0.0138 & -0.0068 & 0.0186 \\
\hline \multirow[t]{2}{*}{ Maneuver } & \multirow{2}{*}{$\begin{array}{c}\text { Design } \\
\text { Execution Time } \\
\text { (UTC) } \\
\end{array}$} & \multicolumn{4}{|c|}{ Estimated $\Delta V$ Vector in EME2000 (Inertial) Coordinates } \\
\hline & & $\begin{array}{c}\mathrm{X} \\
(\mathrm{m} / \mathrm{sec}) \\
\end{array}$ & $\begin{array}{c}\mathrm{Y} \\
(\mathrm{m} / \mathrm{sec}) \\
\end{array}$ & $\begin{array}{c}\mathrm{Z} \\
(\mathrm{m} / \mathrm{sec}) \\
\end{array}$ & $\begin{array}{c}\text { Magnitude } \\
(\mathrm{m} / \mathrm{sec})\end{array}$ \\
\hline TCM 1 & $1 / 10 / 97 \quad 02: 00$ & 16.6367 & -24.4114 & 5.6403 & 30.077 \\
\hline TCM 2 & $2 / 3 / 97 \quad 23: 00$ & 1.1223 & -1.1340 & 0.0365 & 1.5959 \\
\hline TCM 3 & $5 / 7 / 97$ & 0.0764 & 0.0725 & 0.0382 & 0.1120 \\
\hline TCM 4 & $6 / 25 / 97 \quad 17: 00$ & 0.0105 & -0.1374 & -0.0068 & 0.0186 \\
\hline
\end{tabular}

Contingency plans for a possible fifth TCM to be executed in the last day before entry were developed between TCM 2 and 3 . The potential trajectory dispersions to be corrected by this maneuver required rather large lateral $\Delta \mathrm{V}$ magnitudes. Again, it was desired to test performance of this lateral thrusting before any actual TCM 5 execution. So it was decided to perform TCM 3 in 3 segments - two lateral and one axial. A lateral segment was performed first to test the TCM 5 scenario. Then the axial and second lateral segments were performed to achieve the required total $\Delta \mathrm{V}$ for TCM 3 . No problems were encountered with the first lateral segment, verifying the design approach for TCM 5.

TCM 4 was executed with a single lateral segment followed by an axial segment. Although the required $\Delta \mathrm{V}$ turned out to be very small, it was decided to perform the maneuver in order to minimize the probability of having to do TCM 5. (In fact, TCM 5 was not performed as explained in the section on EDL activities.)

\section{Maneuver Reconstruction}

The actual $\Delta \mathrm{Vs}$ provided by the spacecraft's propulsion system were estimated as part of the on-going orbit determination process using tracking data obtained during and after each TCM. Table 4 shows the best estimates of the actual $\Delta \mathrm{V}$ vectors for TCMs $1-4$. A comparison of these vectors with the design values reveals that maneuver execution was quite accurate for Mars Pathfinder. The magnitude errors achieved in flight ranged from $0.2 \%$ to $4 \%$. Pointing errors, computed as the angle between the design direction and the best estimated direction for the TCMs, were typically less than 0.15 deg with a slightly larger value of just over $0.5 \mathrm{deg}$ for the second lateral segment of TCM 3 . Both of these types of errors were well within the performance requirements levied on the spacecraft's propulsion system.

The total actual $\Delta \mathrm{V}$ used for Mars Pathfinder TCMs was $32.733 \mathrm{~m} / \mathrm{sec}$. This is slightly less than the total design value of $33.944 \mathrm{~m} / \mathrm{sec}$, primarily due to TCM 1 executing at slightly lower than the design magnitude. The actual TCM $\Delta \mathrm{V}$ expenditure was much smaller than the total capacity of the propulsion system and much smaller than the pre-launch TCM $\Delta \mathrm{V}$ budget of $130-145 \mathrm{~m} / \mathrm{sec}(99 \%){ }^{2,7}$ This is due to the 
assumption of constraints for TCM 1 execution that would, in some cases, cause the maneuver to be executed as two separate, large axial burns. This execution mode was inefficient and elevated the pre-launch $\Delta \mathrm{V}$ statistics. The actual TCM $1 \Delta \mathrm{V}$ direction did not violate these constraints, allowing the maneuver to be executed as one turn followed by a single axial burn.

\section{NAVIGATION FOR ENTRY, DESCENT AND LANDING (EDL)}

Pathfinder's direct entry into the Martian atmosphere from its interplanetary trajectory led to a unique coupling between navigation knowledge, targeting to the atmospheric entry interface, and spacecraft activities leading up to and during the descent itself. The development of operational plans and procedures requiring navigation participation for this critical time period is discussed. A history of actual orbit determination results and their interaction with flight team activities at key decision times is presented. The final, best estimate for the spacecraft's entry state based on all tracking data obtained prior to landing is given and compared to solutions available at the earlier decision points. This is also compared to post-landing solutions for the lander's location generated from imaging data and tracking data taken after surface deployment.

\section{Navigation Activities and Timeline for EDL}

Pre-launch analyses had shown that no significant improvement in OD knowledge would occur after TCM 4 execution until the last 48 hours before entry when Mars' gravitational signature would begin to be sensed in the Doppler data at levels greater than typical Doppler noise. Trajectory uncertainties would decrease steadily from this time, with the largest decreases coming in the last 24 hours. This improved trajectory knowledge was put to several important uses. First, it was used to update parameters in the flight software controlling the mechanisms and events for a safe descent and initial surface deployment. These included parameters used in the primary and backup parachute deployment algorithms and the latitude and longitude of the surface impact location. Second, the predicts at the DSN station were updated with the new trajectory profile to increase the chances of remaining in contact with the spacecraft for as long as possible during descent. Finally, two opportunities were inserted to correct any unexpected trajectory deviations by performing a fifth maneuver -TCM 5.

All of these considerations were factored into the operational timeline for the last 2 days before entry shown in Figure 6. Four times were chosen as opportunities for the EDL parameter updates, at roughly 37 hours, 22 hours, 9 hours, and 4 hours before entry. Two windows were identified for possible TCM 5 execution, one at roughly 10 hours (TCM 5A) and the other at roughly 6 hours before entry (TCM 5B). A single time was chosen for the DSN predicts update at 2.5 hours before entry (not shown in Figure 6). The navigation team performed new orbit determination solutions at each of these times to update the trajectory and landing site knowledge. In the case of the EDL parameter updates, the team also calculated the new flight software parameter values. For TCM 5, the team assessed the deviations from the desired landing site and made a recommendation on maneuver execution. 


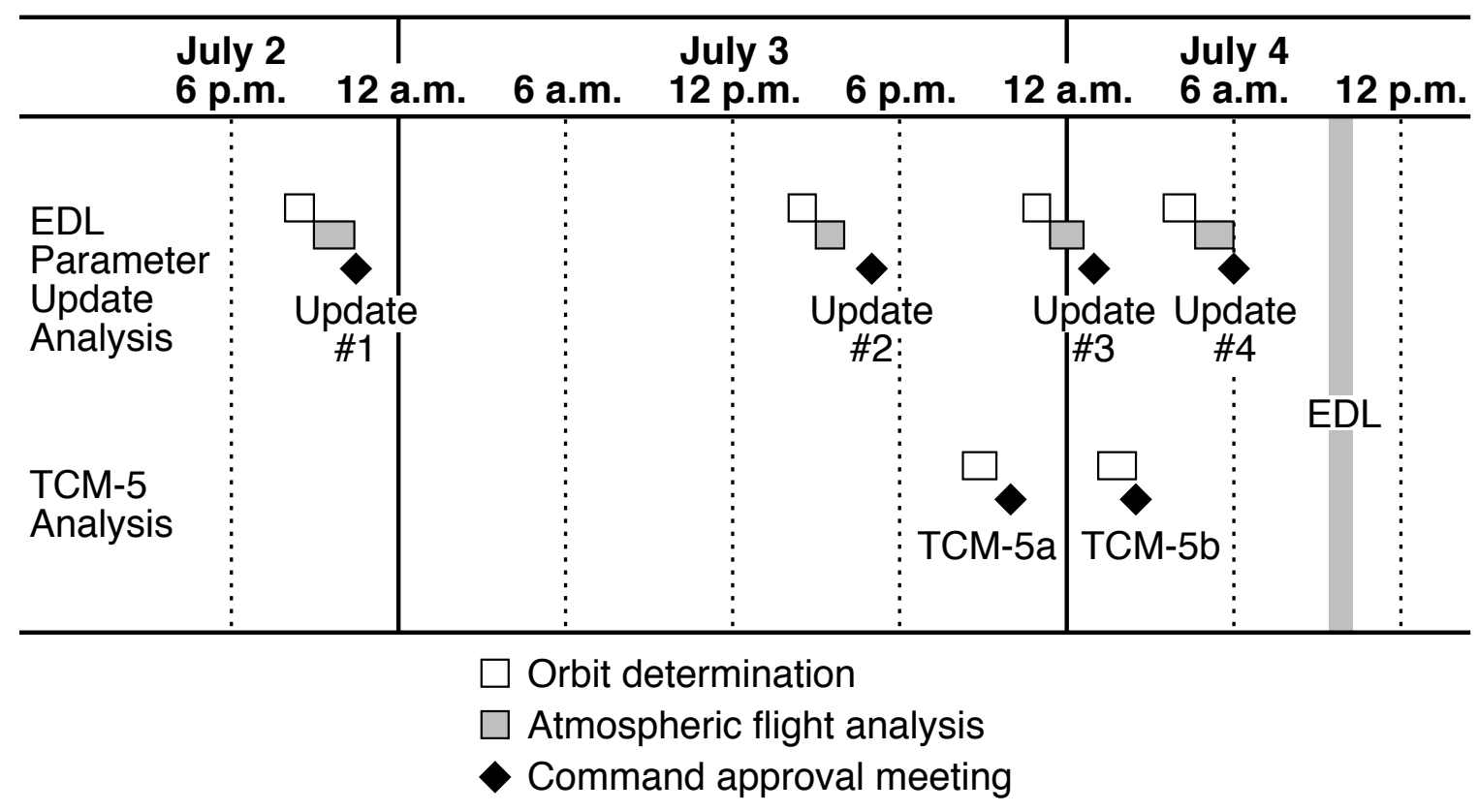

Figure 6 Timeline of Navigation Activities for EDL

The normal maneuver design process for Pathfinder required $3-5$ days of preparation before actually performing the burn. Obviously, there was not enough time to do such a customized maneuver design for the TCM 5 opportunities. Instead, a series of fixed $\Delta V$ s were generated to correct for a specific range of deviations from the desired landing site. It was desired to land within a surface ellipse, or footprint, $200 \times 100 \mathrm{~km}$ in size with the longer axis oriented along the direction of travel of the spacecraft, or downtrack direction. Offsets from the nominal B-plane aimpoint along the B-vector mapped into downtrack dispersions from the target landing site on the surface, while offsets normal to the B-vector mapped into dispersions normal to the spacecraft's direction of travel, or crosstrack dispersions. The B-plane ellipse representing a $6 \sigma$ delivery accuracy for TCM 4 mapped into downtrack offsets well outside the desired footprint, while crosstrack dispersions remained inside it. Therefore, TCM $5 \Delta \mathrm{Vs}$ were initially designed to cover 4 regions for both positive and negative downtrack offsets, giving 8 possible $\Delta \mathrm{V}$ corrections for each of the two TCM 5 windows. Two corrections for crosstrackdeviations, or deviations normal to the B-vector, were later added for the TCM 5A window, bringing the total $\triangle \mathrm{V}$ choices to 10 for TCM 5A and 8 for TCM 5B. Selection of the required $\Delta \mathrm{V}$ was defined by the downtrack and crosstrack offsets or, equivalently the offsets along and normal to the B-vector, predicted from the latest $\mathrm{CD}$ solution. ${ }^{3}$

The set of overall $\Delta \mathrm{V}$ s for TCM 5 downtrack and crosstrack corrections would be implemented using only lateral thrusting given the spacecraft's entry attitude. Attitude control concerns limited the total magnitude of lateral thrusting that could be implemented in a single segment. TCM 5 was to be implemented as a series of one or more lateral $\Delta \mathrm{V}$ pulsing sessions, each applying a uniform $\Delta \mathrm{V}$ increment in the required direction. 2 to 5 of these sessions would be needed to build up the total $\Delta V$ for each of the regions of downtrack or crosstrack offsets. The sequences of commands required to implement each of the $\Delta \mathrm{V}$ choices were designed, tested, and loaded on the spacecraft well 
before the July 4th arrival date. This reduced the necessary activities to simply generating a new OD solution and identifying which of the available $\Delta \mathrm{Vs}$, if any, to apply.

The strategy for generating trajectory files for updates to the DSN predict products was similar to that of TCM 5 design. A series of descent trajectory files and the corresponding predict product sets covering the expected range of flight-path angle dispersions were generated several weeks in advance of landing day. A total of 21 cases were included, representing flight-path angles from $-15.2^{\circ}$ to $-13.2^{\circ}$ in increments of $0.1^{\circ}$. The predicted entry flight-path angle from the OD solution at the designated time was used to select the predict set corresponding to the nearest flight-path angle value. Telecom equipment at the DSN stations was then reconfigured to use this set. The update time was chosen to allow sufficient time for this reconfiguration before receipt of the first signals after entry. ${ }^{11}$

Updated values for parameters used in the primary and backup parachute deployment algorithms in the EDL flight software were determined from the deceleration history during the initial descent into the atmosphere. The deceleration information was derived from propagation of sample entry states representing $3 \sigma$ dispersions from the predicted entry state of the latest $O D$ solution. The resulting sample descent trajectories were generated using the NASA-Langley 6DOF POST program, ${ }^{12}$ with the JPL 3DOF AEP program $^{8}$ serving as a backup and validation for the POST results. Updated values for the landing site latitude and longitude were taken from the AEP and POST propagations of the predicted entry state through the complete descent ending at surface impact. As was the case for TCM 5, the entry analyses associated with generating these parameter updates were normally quite labor-intensive. Processes for running POST and AEP to calculate the deceleration history and associated quantities were largely automated prior to landing day to provide the quick turn-around needed to meet the update schedule. Criteria were established for determining when the new parameter values were sufficiently different from current values loaded in the flight software to justify performing the update. These criteria along with further details on the parachute deployment algorithms and the entry analysis tools are given in (Ref 13).

\section{Orbit Determination Results for the Last 24 Hours}

The orbit determination process was the central focus for the navigation team in the days following execution of TCM 4 and leading up to EDL. Key decisions rested on the latest predictions of spacecraft entry state and landing site along with their associated uncertainties. Numerical results from the actual OD runs performed from July 2 to 4 , 1997 are presented in Tables 5 and 6 . Table 5 gives the predicted B-plane positions and times of closest approach and their associated uncertainties, as was done in Table $2 .^{\dagger}$ Because of the importance of entry flight-path angle (FPA) at this stage of the mission, predictions and uncertainties for it are also given in Table 5. For a landing mission like Pathfinder, navigation uncertainties are more directly viewed in terms of surface ellipses, or footprints, centered around a predicted landing site. Centers and sizes for the footprints corresponding to the B-plane error ellipses are given in Table 6. A graphical

\footnotetext{
$\dagger$ The times of closest approach are a convenient representation of a future interplanetary trajectory that assumes only gravitational forces from Mars. The spacecraft entered the Mars atmosphere, causing the actual trajectory to deviate from this predicted trajectory, before this closest approach time was reached.
} 
history of these runs is shown in the B-plane in Figure 7 and on the surface in Figure 8. These figures clearly illustrate the consistency of the OD results obtained at each of the EDL decision points.

The largest ellipse and footprint in Figures 7 and 8 are from the run generated for the first EDL parameter update on July 2. This was the first time that the navigation team had generated results based on the final solar pressure model. Most of the new parameter values computed from this entry state were acceptably close to the nominal values, but the backup parachute deployment time differed from the nominal value by almost $9 \mathrm{sec}$. This was enough to justify sending the new parameter set to the spacecraft. Due to the consistency of the subsequent $\mathrm{OD}$ solutions, new parameter values remained very close to the values for Update \#1 and no more updates were needed. The parameter values used for EDL Update \#1 became the values used onboard the spacecraft during its descent to the surface; these values are listed in Table 2 of (Ref. 13).

By the times of the TCM 5A and 5B decisions, the OD solution footprints had become almost completely contained in the target footprint. The default criteria indicated that TCM 5 was not necessary and the NAV team recommended that no TCM be performed. TCM 4 became the final maneuver performed by the Pathfinder spacecraft. Predictions of the entry flight-path angle continued to yield values around $-13.9^{\circ}$ for OD solutions leading up to the selection time for the DSN predicts update. The trajectory file for a $-13.9^{\circ}$ entry FPA was chosen as the closest match given the $0.1^{\circ}$ increments separating these pre-generated files.

The NAV team continued to generate OD solutions as new tracking data were received, right up to the last minutes before entry. The final best estimate from pre-entry tracking data used 2-way Doppler data taken up to 1.3 hours before entry and range collected until 3.37 hours before entry. This case is labeled "All data" in Tables 5 and 6. The size of the landing footprint had diminished considerably with incorporation of the later data as shown in Figure 9. The new landing footprint was only $15 \times 8 \mathrm{~km}$ assuming no dispersions due to atmosphere or vehicle aerodynamic mismodeling. This assumption was valid for earlier OD solutions where entry state uncertainties dominated the footprint size. As knowledge of the entry state improved, the relative significance of these dispersions increased. The second ellipse shown in Figure 9 represents the results of a Monte-Carlo analysis of the entry trajectory that incorporated appropriate uncertainties in aerodynamic and atmospheric conditions. The size of the predicted landing footprint doubles when these effects are included, as seen from the entry labeled "All data + descent dispersions" in Table 6.

Independent estimates of Pathfinder's landing location have been computed using data taken after surface deployment. The first of these is derived by triangulation from surface features identified in images taken by the lander's camera. ${ }^{13}$ The second estimate is derived by processing Doppler and range measurements from Pathfinder obtained between July and September 1997 along with similar data from the Viking landers. ${ }^{15}$ These two estimates of landing site location are shown in Table 6 under the labels "Image Triangulation" and "Surface Tracking Data" and marked on Figure 9. These solutions are reasonably consistent with the final navigation results, especially when descent dispersions are included in the estimate. All solutions give points roughly southwest of and less than $30 \mathrm{~km}$ from the target landing site. 
Table 5 B-PLANE STATE, TIME OF CLOSEST APPROACH, ENTRY FLIGHT-PATH ANGLE (FPA) AND THEIR 1 $\sigma$ UNCERTAINTIES FOR EDL OD SOLUTIONS

\begin{tabular}{|c|c|c|c|c|c|}
\hline Solution & $\begin{array}{l}\text { Data Cutoff* } \\
\text { (UTC) }\end{array}$ & $\begin{array}{l}\mathrm{B} \cdot \mathrm{R} \\
(\mathrm{km}) \\
\end{array}$ & $\begin{array}{l}\mathrm{B} \cdot \mathrm{T} \\
(\mathrm{km}) \\
\end{array}$ & $\begin{array}{c}\text { TCA } \\
\text { (UTC } \\
\text { on } \quad 7 / 4 / 97) \\
\end{array}$ & $\begin{array}{l}\text { FPA } \\
\text { (deg) }\end{array}$ \\
\hline TCM 4 & $6 / 23 / 97$ & -1852.63 & -4250.28 & $16: 54: 22.6$ & -14.8408 \\
\hline Update \#1 & $\begin{array}{c}7 / 2 / 97 \\
19: 46 \\
\end{array}$ & -1842.67 & -4275.09 & $16: 54: 22.6$ & -13.9423 \\
\hline Update \#2 & $\begin{array}{c}7 / 3 / 97 \\
18: 48 \\
\end{array}$ & -1841.28 & -4276.58 & $16: 54: 22.6$ & -13.9019 \\
\hline TCM 5A & $\begin{array}{c}7 / 4 / 97 \\
02: 54\end{array}$ & -1844.19 & -4275.45 & $16: 54: 22.6$ & -13.8960 \\
\hline Update \#3 & $\begin{array}{c}7 / 4 / 97 \\
04: 46 \\
\end{array}$ & -1844.27 & -4275.43 & $16: 54: 22.594$ & -13.8955 \\
\hline TCM 5B & $\begin{array}{c}7 / 4 / 97 \\
07: 46 \\
\end{array}$ & -1844.52 & -4275.27 & $16: 54: 22.589$ & -13.8979 \\
\hline Update \#4 & $\begin{array}{c}7 / 4 / 97 \\
10: 46 \\
\end{array}$ & -1844.58 & -4274.46 & $16: 54: 22.516$ & -13.9139 \\
\hline All data & $\begin{array}{c}7 / 4 / 97 \\
15: 41\end{array}$ & -1850.17 & -4269.23 & $16: 54: 22.386$ & -14.0614 \\
\hline Solution & $\begin{array}{c}1 \sigma \\
\text { SMAA } \\
(\mathrm{km}) \\
\end{array}$ & $\begin{array}{c}1 \sigma \\
\text { SMIA } \\
(\mathrm{km})\end{array}$ & $\begin{array}{c}\theta \\
(\operatorname{deg}) \\
\end{array}$ & $\begin{array}{c}1 \sigma \\
\text { TCA } \\
(\mathrm{sec}) \\
\end{array}$ & $\begin{array}{c}1 \sigma \\
\text { FPA } \\
(\text { deg })\end{array}$ \\
\hline TCM 4 & 17.44 & 4.192 & 109.59 & 0.38 & 0.212 \\
\hline Update \#1 & 13.303 & 2.615 & 108.016 & 0.227 & 0.146 \\
\hline Update \#2 & 8.542 & 2.127 & 114.077 & 0.158 & 0.104 \\
\hline TCM 5A & 5.816 & 1.357 & 126.059 & 0.115 & 0.0899 \\
\hline Update \#3 & 5.674 & 1.254 & 127.266 & 0.113 & 0.0893 \\
\hline TCM 5B & 5.380 & 1.117 & 129.268 & 0.108 & 0.0891 \\
\hline Update \#4 & 5.106 & 1.052 & 130.576 & 0.103 & 0.0886 \\
\hline All data & 3.246 & 0.176 & 114.972 & 0.023 & 0.00960 \\
\hline
\end{tabular}

* These are the times that the last data were received on Earth; the measurement was actually collected at the spacecraft 10 minutes and 40 seconds earlier, which was the one-way light time value at entry on July 4.

\section{CONCLUSIONS}

All of the requirements placed on Mars Pathfinder navigation were met with ample margins. The lander came to rest within $30 \mathrm{~km}$ of the target location, well within the required footprint of $300 \times 100 \mathrm{~km}$ and the smaller goal of $200 \times 100 \mathrm{~km}$. The final estimated flight-path angle at entry was $-14.06^{\circ}$, just $0.14^{\circ}$ off from the nominal value of $-14.2^{\circ}$ and well within the required $1^{\circ}$ dispersion from the nominal. The total $\Delta \mathrm{V}$ used for trajectory corrections was $32.7 \mathrm{~m} / \mathrm{sec}$, well under the $105 \mathrm{~m} / \mathrm{sec}$ limit. 
Table 6 LANDING SITE AND 3o SURFACE FOOTPRINTS FOR EDL OD SOLUTIONS

\begin{tabular}{|l|c|c|c|c|c|}
\hline Solution & $\begin{array}{c}\mathrm{E} \\
\text { Longitude } \\
(\mathrm{deg})\end{array}$ & $\begin{array}{c}\text { Aerocentric } \\
\text { N Latitude } \\
(\mathrm{deg})\end{array}$ & $\begin{array}{c}3 \sigma \\
\text { Downtrack } \\
(\mathrm{km})\end{array}$ & $\begin{array}{c}3 \sigma \\
\text { Crosstrack } \\
(\mathrm{km})\end{array}$ & $\begin{array}{c}\text { Footprint } \\
\text { Orientation } \\
\text { Angle } \\
(\mathrm{deg})\end{array}$ \\
\hline \hline Target & 326.9 & 19.244 & $\mathrm{~N} / \mathrm{A}$ & $\mathrm{N} / \mathrm{A}$ & $\mathrm{N} / \mathrm{A}$ \\
\hline \hline TCM 4 & 328.5647 & 19.8456 & 185.661 & 72.927 & 10.683 \\
\hline Update \#1 & 326.2294 & 18.8238 & 154.209 & 51.784 & 8.21 \\
\hline Update \#2 & 326.1944 & 18.7629 & 112.565 & 37.400 & 20.586 \\
\hline TCM 5A & 326.1634 & 18.7924 & 98.301 & 18.606 & 29.460 \\
\hline Update \#3 & 326.1617 & 18.7929 & 97.759 & 16.931 & 29.896 \\
\hline TCM 5B & 326.1671 & 18.7985 & 97.600 & 12.988 & 30.423 \\
\hline Update \#4 & 326.2063 & 18.8291 & 96.607 & 12.988 & 29.836 \\
\hline All data & 326.5875 & 19.0438 & 15.116 & 8.395 & 84.457 \\
\hline $\begin{array}{l}\text { All data + descent } \\
\text { dispersions }\end{array}$ & 326.48 & 19.004 & 41.458 & 14.807 & 18.631 \\
\hline Image Triangulation & 326.45 & 19.14 & $\mathrm{~N} / \mathrm{A}$ & $\mathrm{N} / \mathrm{A}$ & $\mathrm{N} / \mathrm{A}$ \\
\hline $\begin{array}{l}\text { Surface } \\
\text { Data }\end{array}$ & 326.4762 & 19.095 & $\mathrm{~N} / \mathrm{A}$ & $\mathrm{N} / \mathrm{A}$ & $\mathrm{N} / \mathrm{A}$ \\
\hline
\end{tabular}
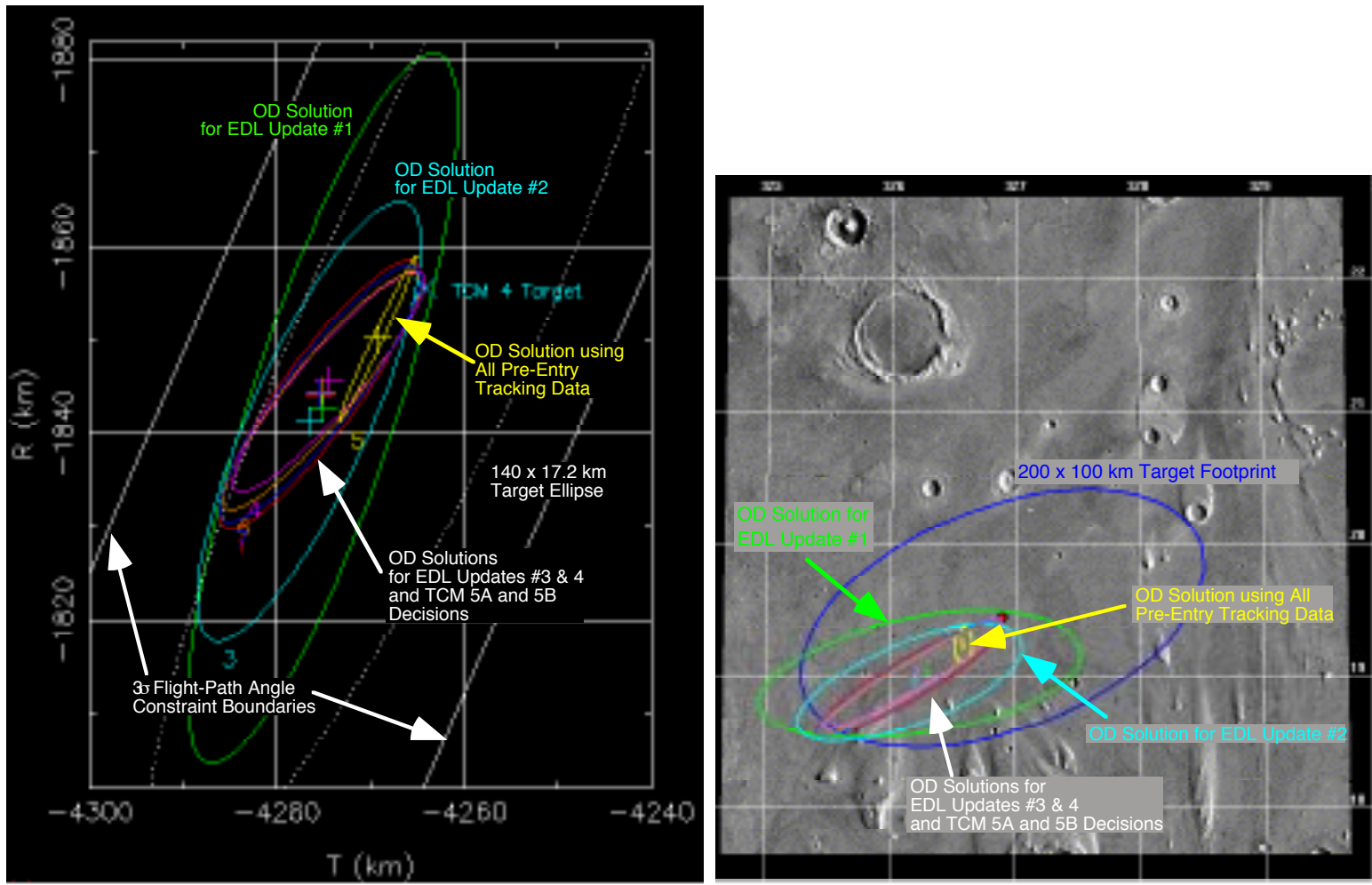

Figure 7 1 $1 \sigma$ B-Plane Error Ellipses

Figure 8 Predicted 3o Surface Footprints for EDL OD Solutions 


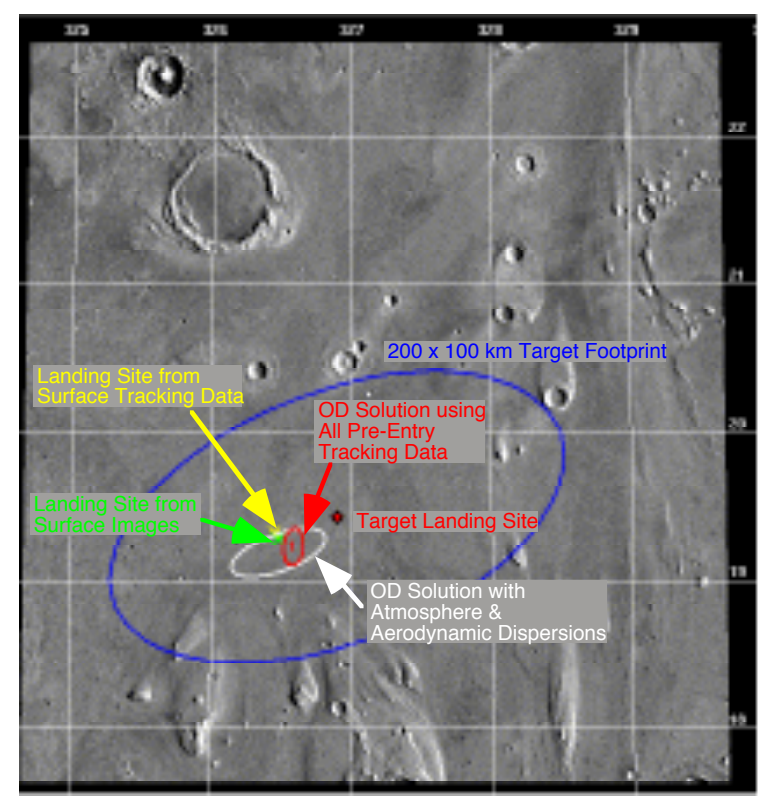

Figure 9 Best Estimates of Pathfinder's Landing Site

One of the major accomplishments of Mars Pathfinder navigation was the successful implementation of the "enhanced filter" configuration and the precision ranging technique for spacecraft orbit determination. These methods allowed the necessary $\infty$ accuracy to be achieved using only Doppler and ranging without the addition of other data types such as optical images or $\Delta \mathrm{VLBI}$. Pathfinder has validated the use of this filter configuration for actual flight operations.

Another significant accomplishment was the integration of existing navigation software for modeling an interplanetary trajectory with new software for modeling the descent trajectory once in the atmosphere. The JPL AEP and the NASA/Langley POST programs were critical additions to the navigation software suite. Coordinated used of these programs was necessary to target the late cruise maneuvers for a landing at the desired surface location. This enhanced software tool set also allowed optimization of the spacecraft's descent conditions based on rapid and frequent orbit determination updates using the latest available tracking data in the final hours before entry.

\section{ACKNOWLEDGMENT}

The work described in this paper was performed at the Jet Propulsion Laboratory, California Institute of Technology, under contract with the National Aeronautics and Space Administration.

\section{REFERENCES}

1. Kallemeyn, P. H., "Mars Pathfinder Navigation Plan," (internal document), JPL D 11349, PF-220-NP, July 1994.

2. Kallemeyn, P., Spencer, D.A., Vaughan, R., and Helfrich, C., "The Mars Pathfinder Navigation System," paper AIAA 96-3656, AIAA/AAS Astrodynamics Specialist Conference, San Diego, CA, July 29-31, 1996. 
3. Kallemeyn, P., Vaughan, R., Spencer, D., and Braun, R., "Mars Pathfinder Navigation Report," (internal document), JPL IOM 312.98.A-030, January 9, 1998.

4. Kallemeyn, P., and Vaughan, R., "Observing Doppler to Verify Attitude Behavior," (internal document), JPL IOM 312.3-96-028, November 26, 1996.

5. Estefan, J. A., Pollmeier, V. M., and Thurman, S. W., "Precision X-Band Doppler and Ranging Navigation for Current and Future Mars Exploration Missions," paper AAS 93-250, AAS/AIAA Astrodynamics Specialist Conference, Victoria, B.C., Canada, August 16-19, 1993.

6. Thurman, S. W. and Pollmeier, V. M., "Guidance and Navigation for the Mars Pathfinder Mission," Acta Astronautica, Vol 35, pp. 545-554.

7. Spencer, D. A., "Mars Pathfinder Maneuver Design and Propellant Budget," (internal document), JPL IOM 312/96.2-006, May 31, 1996.

8. AEP Version 1.0 User's Guide, (internal document), JPL, October 15, 1993.

9. Wang, T. C., Stanford, R. H., Sunseri, R. F., Breckheimer, P. J., "Survey of Optimization Techniques for Nonlinear Spacecraft Trajectory Searches," paper AIAA 88-4285-CP, AIAA/AAS Astrodynamics Specialist Conference, Minneapolis, MN, 1988.

10. Spencer, D. A., and Braun, R. D., "Mars Pathfinder Atmospheric Entry: Trajectory Design and Dispersion Analysis," AIAA Journal of Spacecraft and Rockets, Vol 33, Number 5, pp 670-676.

11. Wood, G. E., Asmar, S. W., Rebold, T. A., and Lee, R. A., "Mars Pathfinder Entry, Descent, and Landing Communications," (internal document), JPL TDA Progress Report 42-131, November 15, 1997.

12. Brauer, G., Cornick, D., and Stevenson, R., "Capabilities and Applications of the Program to Optimize Simulated Trajectories (POST)," NASA CR-2770, Feb. 1977.

13. Braun, R. D., Spencer, D.A., Kallemeyn, P. H., and Vaughan, R. M., "Mars Pathfinder Atmospheric Entry Navigation Operations," paper AIAA 97-3663, 1997 AIAA GNC, AFM, and MST Conference and Exhibit, New Orleans, LA, August 11-13, 1997.

14. Golombek, M. P., et. al., "Overview of the Mars Pathfinder Mission and Assessment of Landing Site Predictions,", Science, Vol. 278, December 5, 1997, pp. 1743 1748 .

15. Folkner, W. M., Yoder, C. F., Yuan, D. N., Standish, E. M., and Preston, R. A., "Interior structure and Seasonal Mass Redistribution of Mars from Radio Tracking of Mars Pathfinder," Science, Vol. 278, December 5, 1997, pp 1749-1752. 